\title{
Healthcare wearable devices: an analysis of key factors for continuous use intention
}

\author{
Sang M. Lee ${ }^{1} \cdot$ DonHee Lee $^{2}$ (D) \\ Received: 21 July 2020 / Accepted: 6 October 2020 / Published online: 15 October 2020 \\ (c) Springer-Verlag GmbH Germany, part of Springer Nature 2020
}

\begin{abstract}
This study empirically examined the effects of internal and external factors on actual use behavior, health improvement expectancy, and continuous use intention of healthcare wearable devices. The study proposed a research model with its associated hypotheses that were tested using structural equation modeling. We also performed a comparative analysis of the two sample groups (medical personnel and general public), based on data collected from 288 healthcare wearable devices/apps users. The findings of the study indicated that internal and external factors have positive effects on actual use behavior, and health improvement expectancy and continuous use intention of healthcare wearable devices can be promoted through actual use behavior. The comparative analysis of the two groups showed that medical personnel had higher relationships among the study factors than general public. The study results shed theoretical and practical implications regarding how healthcare wearable devices or apps can be effectively used for disease prevention and health management for the users.
\end{abstract}

Keywords Healthcare wearable devices · Continuous use intention · User experience $\cdot$ A multi-group analysis

\section{Introduction}

With the rapid advances in mobile technology, the use of mobile devices has skyrocketed. It is estimated that more than $70 \%$ of the world's population use mobile devices (Ericsson 2017). Markets and Markets (2017) predicts that the global mobile

DonHee Lee

dhlee04@inha.ac.kr

Sang M. Lee

slee1@unl.edu

1 College of Business, University of Nebraska-Lincoln, Lincoln, NE, USA

2 College of Business Administration, Inha University, 100 Inharo, Michuhol-gu, Incheon, South Korea 
healthcare market will grow from USD 63.4 billion in 2013 to 90.4 billion in 2022 . According to Strategy Analytics (2019), global smartwatch shipments reached 12.3 million units in June 2019, representing a 44 percent increase from 8.6 million units in June 2018. Wearable devices are becoming an increasingly popular platform for healthcare services, particularly given the increasing interest in health, well-being, disease prevention, and fitness, as well as the paradigm shift toward healthcare that is personalized and controlled by individuals (Lee 2018). Furthermore, the shift in the medical paradigm, from disease treatment to prevention and health management, has provided the users of wearable devices new experiences that are not available from traditional healthcare-related products and services (Lee 2019).

Today's digital wearables, converged products of smart sensors, artificial intelligence (AI), the Internet of Things (IoT), big data, robots, and radar technologies, can help manage and prevent diseases. They can measure the heart rate, body temperature, blood pressure, and respiration of the elderly living in homes and facilities, and by detecting their risk indicators, such as worsening disease conditions, falls, and other life-threatening situations (O'Donovan et al. 2009; Pataranutaporn et al. 2019). As such, many companies have developed wearables and smartphone apps to provide a wide range of healthcare services, and this trend is expected to accelerate (Braithwaite 2018). Despite the rapid growth of the healthcare wearable devices market, the adoption of these devices and related technologies is diverse as different social segments and countries have varying degrees of socio-technical development (Yoon et al. 2020). In addition, previous studies on healthcare wearable devices and their applications generally focused on specific age groups (e.g., younger generations), using the technology acceptance model (TAM), TAM2, Unified Theory of Acceptance and Use of Technology (UTAUT), and UTAUT2 models, or the analysis of technology or market trends (Wang et al. 2009). There is little empirical research on user acceptance behavior and the actual use of such wearable devices.

It is important to identify factors affecting the continuous use intention for healthcare wearable devices. New technologies can increase in value only when they are widely disseminated in the market which induces further product advancements. The diversification of available products helps reduce user burden, especially from a financial standpoint. In addition, the success of healthcare applications is determined by continuous use intention, not just technology acceptance or adoption rates. Therefore, it is imperative to examine post-adoption attitudes, such as use intention and its relationship to user characteristics.

Empirical research on the key factors affecting user acceptance behavior is needed to sustain the use of, and interest in, healthcare applications of wearable devices. There is a paucity of empirical research on the actual use behavior, health improvement expectancy, and continuous use intention of new healthcare devices. This study intends to address the limitations of previous studies by identifying the behavioral differences about healthcare wearables between the two groups: those who are exposed to disease treatment environment (medical personnel) and those who are not (general public). In addition, to differentiate this study from previous ones, its focus will be on disease prevention, by analyzing the actual behavior and continuous use intention. To achieve the research objectives, this study develops a research model based on the Knowledge, Attitudes, Practices, and Beliefs (KAPB) 
model, a frequently used method in the development and delivery of health education programs for preventive activities, the UTAUT2 model related to the acceptance of new technologies, and Theory of Planned Behavior (TPB). This study attempts to answer the following three research questions: (1) Do the internal and external activities associated with using a healthcare wearable device impact the actual use behavior of the device? (2) Does the actual use of a healthcare wearable device have an impact on the user's health improvement expectancy? (3) Does the user's health improvement expectancy (if any) attained by using a healthcare wearable device? A research model is proposed to answer these questions. The results of the study are expected to contribute to both theory and practice regarding the usage of healthcare wearable devices for health improvement and disease prevention.

The rest of this paper is organized as follows. In Sect. 2, the relevant literature is reviewed. Sect. 3 proposes a research model with associated hypotheses. In Sect. 4, research methodology and the results of the analysis are presented. We conclude the study in Sect. 5 with discussion of the results, implications, limitations of the study, and future research needs.

\section{Literature review}

Healthcare devices are expected to support not only the growing need for remote medical services without spatial and temporal restrictions but also the increased demand for medical services among senior citizens who suffer from reduced mobility and a lack of access to professional medical services (Panner 2019). There are many factors that influence the expansion of the remote healthcare market like the aging baby boomer generation, the largest age group in the United States, as well as the increasing number of people with chronic diseases such as diabetes and cardiovascular issues (Panner 2019). In addition, the expansion of remote medical services is expected to gain momentum as $5 \mathrm{G}$ technology, which became commercially available in 2019, that can expand the location coverage (Lee 2019). The current COVID-19 pandemic has further highlighted the significance of remote healthcare delivery (Chadha et al. 2020; Cohen et al. 2020).

Wearable technology refers to information technology (IT) enabled devices that can be carried on the user's body, such as the wrist, arm, or head (O'Donovan et al. 2009; Pataranutaporn et al. 2019). Advances in wearable technology and the growing demand from consumers who wish to manage their own health have profoundly influenced the healthcare industry including insurers, providers, and technology companies (Phaneuf 2020). It is expected that the demand for products and services using digital health technology for the aged will continue to expand. Such increased demand is also reflected in the accelerating availability of a range of healthcare wearable devices and applications, as well as the increasing number of global digital health startups. 


\subsection{The healthcare industry and wearables}

With the popularization of smartphone use, applications of wearable technology have exploded, converged with artificial intelligence (AI), IoT, and smart sensing. Today, they are widely used not only in the healthcare industry but also in gaming, communications, industrial operations, and safety. For example, in healthcare, IBM offers a wide variety of mobile services through its Mobile Wireless Health Solutions, and GE Healthcare has developed Vscan to provide more accurate and faster healthcare services that are not constrained by time and place. Wearable devices in healthcare include various forms, including wearable fitness trackers, smart health watches, wearable ECG monitors, wearable blood pressure monitors, and biosensors (Phaneuf 2020). The development of smartphone apps has helped provide a wide range of healthcare services and this trend is expected to accelerate in the future (Braithwaite 2018). Apple's Watch 5, Galaxy Watch Active 2 of Samsung Electronics, Fitbit's Versa 2, and Xiaomi's Mi Band 4 are good examples. Yoon et al. (2020) reviewed current usage areas of wearable devices such as medical (e.g., diagnostic and therapeutic areas), sports, fitness and wellness.

The use of wearables as medical devices rather than simple healthcare devices takes various forms (O'Donovan et al. 2009; Pataranutaporn et al. 2019; Yoon et al. 2020). First, wearable health devices can be accessories, such as a wristwatch. The main function of accessories used by most users is for well-being and fitness. Detailed functions include the ability to sync to smartphone applications; store and manage information on key data points, notably the user's psychological status; monitor sleep patterns; track calories burned and consumed; and record distance traveled.

Second, wearable health devices can be in the form of clothing. Smart clothing, which uses computer chips to exchange electrical signals and data, or uses special materials to connect with a smartphone to apply various functions, can measure changes in blood flow, biological rhythm, breathing, and the health of their users and accumulate data (Patel et al. 2012; Phaneuf 2020; Yoon et al. 2020).

Third, wearable health devices can be attached to the body. Sensimed, a Swiss firm, puts a contact lens-type medical device on glaucoma patients to measure their intraocular pressure for 24/7. Changes in the intraocular pressure are the most important factor in diagnosing glaucoma, and its progression can be slowed down through continuous monitoring of the intraocular pressure. These contact lenses use sensors and antennas inside the lens to measure the intraocular pressure of the user, transmit and record the data to a smart device in real-time, and store it on the doctor's computer via Bluetooth (Patel et al. 2012; Phaneuf 2020).

Fourth, there are biopsy wearables. The most advanced wearables can be transplanted in the user's body or be consumed by users. Currently, technologies of this type include ingestible sensors on the patient's medication to ascertain if the medication is being ingested in real-time, and technology that allows a wireless sensor to be implanted on the skin to confirm real-time changes in blood sugar levels for patients who need to be constantly monitored, such as patients with diabetes.

The growing demand for healthcare services due to the aging population is fueling the adoption and use of digital health in the care and treatment of elderly 
citizens (O’Donovan et al. 2009; Pataranutaporn et al. 2019). Healthcare wearables can also support the remote healthcare sector so that individuals may receive healthcare services without restrictions on time and space. Moreover, they hold promise as a solution to such issues as a lack of access to professional medical personnel and for the elderly with limited mobility. Gary Shapiro, President and CEO of the Consumer Technology Association, stated at the 2018 Hearing Loss Association of America (HLAA) Convention in Minneapolis that "... the use of personal health devices, such as wireless blood pressure sensors and electrocardiographic sensors, is much more cost-effective and accurate, and a remote patient monitoring system receives real-time patient data and allows doctors to treat patients more effectively compared to when patients visit hospitals" (Shapiro 2018). This suggests that digital healthcare technology can help relieve the intensifying lack of healthcare workers and healthcare facilities caused by the aging population. There is an increasing trend of interest in health monitoring technology and virtual care techniques, which can result in significant cost savings to healthcare institutions and insurance companies (O'Donovan et al. 2009). Thus, the potential for the growth of wearables in the healthcare industry is significant.

The global market for healthcare wearable devices is expected to grow at an annual growth rate of 30 percent, from 2.5 billion dollars in 2015 to 12 billion dollars by 2020. Despite the explosion of interest in health wearables, there is currently no specific agreement on the research, terminology, and the scope of applications to both well-being and health management.

\subsection{Healthcare wearable devices and applications}

Pataranutaporn et al. (2019, p. 3327) suggested that "wearable technology has enabled on-body real-time sensing and computing of human physiological information." Phaneuf (2020) reported that wearable technology, including electronic devices in healthcare, is designed to collect data on users' personal health and exercise. Phaneuf (2020, p. 1) defined a healthcare wearable technology as “...consumers can wear, like Fitbits and smartwatches, and are designed to collect the data of users' personal health and exercise." Ravindra (2019, p. 1) defined it as “... that is noninvasive and autonomous, which performs a particular medical function, be it support or monitoring, over a prolonged time period." These definitions of healthcare wearable devices imply that a healthcare wearable device can help prevent disease and review the user's health conditions. In addition, a healthcare wearable device can be attached to the body or combined into a part of the body to enhance and supplement the healthcare capabilities of the human body and be adjusted according to the user's willingness.

Dunsmuir et al. (2014) defined a healthcare application as the use of smartphone apps and sensors to predict infection or disease to help its users take appropriate actions, and Gücin and Berk (2015) defined it as an activity that assists healthcare professionals with making medical decisions and providing healthcare education. A healthcare application refers to a task that focuses on shaping consumer health habits, by providing information on such activities as stop smoking, exercise, and diet 
(Aitken and Lyle 2015). To prevent the spread of the COVID-19 global pandemic smartphone apps have been effectively used for contact tracing of infected individuals or monitor those in involuntary isolation. The common factor in the studies cited above is that they all explored technology acceptance and use intentions. However, the intention is the will of the individual and may or may not lead to actual behavior to use. As such, there is a need to examine the actual conversion from intention to behavior. Since new technologies are to be disseminated in the market, it is also essential to identify factors influencing use intention to examine whether the intention actual resulted in behavior.

This study focuses on users who use healthcare applications or devices. Consequently, in this study, a healthcare application or device is defined as a mobile-based healthcare application or device used to provide information, measurement, and management of physical and exercise data as well as other healthcare-related content required for personal health management.

\subsection{Technology acceptance model (TAM)}

TAM has theoretical foundations on theory of reasoned action (TRA) from social psychology (Fox and Connolly 2018). To analyze user behavior regarding the acceptance of new technologies, we utilized the two concepts from TAM: perceived ease of use and perceived usefulness. Specifically, we assumed that when more users feel that a specific system is both easy to use and useful, it would positively influence attitudes toward, and the use intention of, the system (Davis et al. 1992). Although TAM has been widely used and applied in studies of user intentions and behaviors regarding the acceptance of new technology, it had been noted repeatedly that TAM cannot be used to measure actual use intentions. This criticism led to the development of TAM2 (Venkatesh and Davis 2000). Taylor and Todd (1995) suggested the Decomposed Theory of Planned Behavior (DTPB) based on theory of planned behavior (TPB) and beliefs factors (behavior, normative, and control beliefs) to predict the user's behavioral intention and actual use behavior of a new system.

Venkatesh et al. (2003) proposed Unified Theory of Acceptance and Use of Technology (UTAUT) to ascertain the limitations of TAM and TAM2 models. UTAUT is a model that merges multiple theoretical models that can be used to investigate new technology acceptance, including TRA, TAM, the business motivation model, TPB, the Model of PC Utilization, innovation diffusion theory, and social cognitive theory (Venkatesh et al. 2003, 2012; Al-Tarawneh 2019). As factors influencing user intention and behavior, UTAUT included effort expectancy, performance expectancy, social influence, and facilitation condition, as well as voluntariness of use, age, gender, and experience as moderating variables.

However, as with TAM, UTAUT was also criticized for not being able to include all the variables related to technology use. Therefore, Venkatesh et al. (2012) developed UTAUT2, which includes the three factors of hedonic motivation, price value, and habit. The main difference between UTAUT and UTAUT2 is that UTAUT is a model developed for explaining acceptance intent and use in the organizational context, while UTAUT2 is a model for improving the predictability of technology and 
service acceptance and use in a consumer-use context. Through empirical analysis, Venkatesh et al. (2012) found that UTAUT2 was a better predictor than UTAUT of acceptance intention, increasing the explained variance from 56 to $74 \%$, and of technology use from 40 to $52 \%$. However, it is also necessary to identify use intentions by including the perception, attitudes, and expected values of consumers regarding their acceptance of new technologies.

Based on the UTAUT model in healthcare system, Cimperman et al. (2016) found that health improvement expectancy, facilitation conditions, effort expectancy, and perceived security directly impact use intentions. However, in a study that analyzed the influence of home-based remote healthcare services for the elderly on service use intention, computer anxiety had a negative influence on effort expectancy. Wilson and Lankton (2004) used TAM to explore info-seeking and Internet dependence as factors that influence use intentions for healthcare-related IT technologies. In a study of factors affecting the acceptance of smart glasses, Rauschnabel et al. (2015) underscored the importance of the functional benefits and social compliance and suggested that people with open and outgoing nature trend to be willing to embrace smart glasses. The features, compatibility, aesthetics, and brand of wearable devices were found to impact perceived benefits and value, and they were found to positively impact the use intention (Yang et al. 2016).

\subsection{Knowledge, Attitudes, Beliefs and Behavior Models and Theory of Planned Behavior}

Many theories have been developed to describe or predict health-related behavior based on the perception that health is affected by social and behavioral factors. The leading models include the Health Belief Model (HBM) and the Knowledge, Attitudes, and Practices (KAP) Model (Humphis 2000).

HBM, was proposed by Rosenstock (1974) and Becker et al. (1977) expanded and further developed it. HBM was originally developed to improve health education programs for general public (Rosenstock, 1974). However, it has become one of the most widely used social cognition models in health psychology (Rosenstock 1974; Becker 1977; Abraham and Sheeran 2015). The HBM suggested by Becker et al. (1977) posits that motivations to initiate and maintain health-protecting behavior are influenced by perception variables, such as personal susceptibility to disease, seriousness, and worries regarding the disease, benefits of taking action, and barriers to behavioral changes (Harris and Garcia-Godoy 2004).

The KAP model is based on HBM, which is the most widely used method for prevention activities designed for the general public. The KAP model is used to evaluate the knowledge, attitudes, and practices of the general public regarding their health behavior, diseases, and health issues using a structured survey (Humphis 2000). Knowledge is a more profound concept than simply understanding, and it includes the acquisition, management, and use of knowledge and technology. Attitude is an acquired factor that includes cognitive, emotional, sensory, and behavioral tendencies (Raina 2013; Rav-Marathe et al. 2016). Practice is defined as applying knowledge and rules to result in a final action (Badran 1995). The KAP model can 
be effectively applied to analyze knowledge gaps, cultural beliefs, and behavior patterns among populations, and it facilitates the understanding of individual experiences, opinions, and behaviors (Johnston and Warkentin 2010; Working Group on Monitoring and Evaluation 2014). However, due to the criticism that the KAP model ignored the role of beliefs in individual actions, the KAPB model was proposed.

The KAPB model incorporates beliefs into KAP. KAPB embodies the perspective that understanding one's own health behavior requires comprehending one's life patterns, and action is supported by acquiring basic health knowledge. KAPB, which began as a theory of learning, is now widely applied to the field of healthcare and emphasizes the importance of appropriate health information as well as positive beliefs and attitudes for good health practices (Frank 2004; Johnston and Warkentin 2010). The KAPB model emphasizes the role of practice for improvement, as effort is required to understand the issues with one's current health behaviors before improving them. Therefore, the KAPB model is often used in health-related fields to provide education for the maintenance and betterment of health, improve attitudes and beliefs, and motivate the intention to act.

However, the relationship between consumer behavior and attitudes has yet to be studied using the KAPB model, which complements HBM and KAP models. The concept of self-efficacy is required to describe the relationship between consumer behavior and attitudes. Self-efficacy refers to the individual's confidence in the ability to perform certain actions (Bandura 1997). The potential for action increases with higher self-efficacy and with positive outcome-expectancy. Therefore, it is necessary to examine the relationship between the attitudes and actions of consumers.

Theory of Planned Behavior (TPB) is a widely known theory that explains the relationship between consumers' attitudes and behaviors. TPB is a concept that expands on the previous TRA without its limitations (Ajzen 1998; Fishbein and Ajzen 2010). TRA posits that attitudes towards behaviors and subjective norms influence behavioral intentions, which then lead to behaviors. However, in reality it is necessary for an individual to be in a certain situation (opportunity) to engage in a behavior (Taylor et al. 2007). TPB was developed to predict behaviors in which individuals have incomplete voluntary control. Concerning self-esteem and self-efficacy, TPB expands on the concept of perceived behavioral control (Ajzen 2002). TPB, similarly to TAM, includes the intention of action; intention refers to the level to which executing specific actions are voluntary and the amount of voluntary effort toward such action (Ajzen 1998).

For the purposes of this study, it is important to note that there is a large volume of research that indicates that both TRA and TPB have utility in predicting health behaviors and that the observed statistical relationships among their internal constructs, which are based on behavioral, normative, and control beliefs, have significance across a wide range of contexts (Armitage and Christian 2003). Both models are based on an individual's attitudes and social norms, as well as the person's perceived control as accurate predictors of behavioral intentions, through an evaluation of the available information (Ajzen 1998; Armitage and Christian 2003). HBM also includes a self-efficacy component to explain health behavior.

Perception, knowledge, and attitudes toward a health issue may influence health behaviors, as explained by HBM and KAPB models. Furthermore, an individual 
requires an expected value from the behavior and self-efficacy to engage in certain behaviors (Bandura 1997). Therefore, to understand consumers' use intentions for digital devices, there are multiple aspects of health, attitudes, knowledge, and practices that are directly connected to actual behavior.

Thus, this study was based on multiple theories discussed in this section as follows. The UTAUT2 model was used to explain new technology acceptance; the KAPB model was used to understand the behaviors associated with implementing health prevention activities, and TPB was used to understand the relationship between consumer attitudes and behaviors.

\section{Research model and hypotheses development}

This study analyzed actual use behaviors and continuous use intentions of healthcare wearable devices from the perspective of disease prevention and health management. Use intention was defined as the user's intention to utilize new products and services, measured through variables that determine actual behavior to use (Davis 1989). However, as this study focuses on analyzing whether current users of healthcare wearable devices will continue to use them in the future, use intention is excluded from the variables that predict actual use behavior. The proposed research model is presented in Fig. 1. The internal factors in the research model were from KAPB, while external factors and user experience were extracted from TPB and UTAUT2. The study examined two groups: medical personnel and general public.

To lead a healthy life, it is necessary for people to engage in health-related behaviors and practices that are habitual activities instead of occasional events. The emergence of various digital devices provides an opportunity to develop healthy life habits. With the increasing diversity in and access to methods of health management, many people are placing importance on user-centric health prevention activities. For health management, related knowledge is a prerequisite to developing good intentions. In general, for health management, it is necessary to obtain accurate

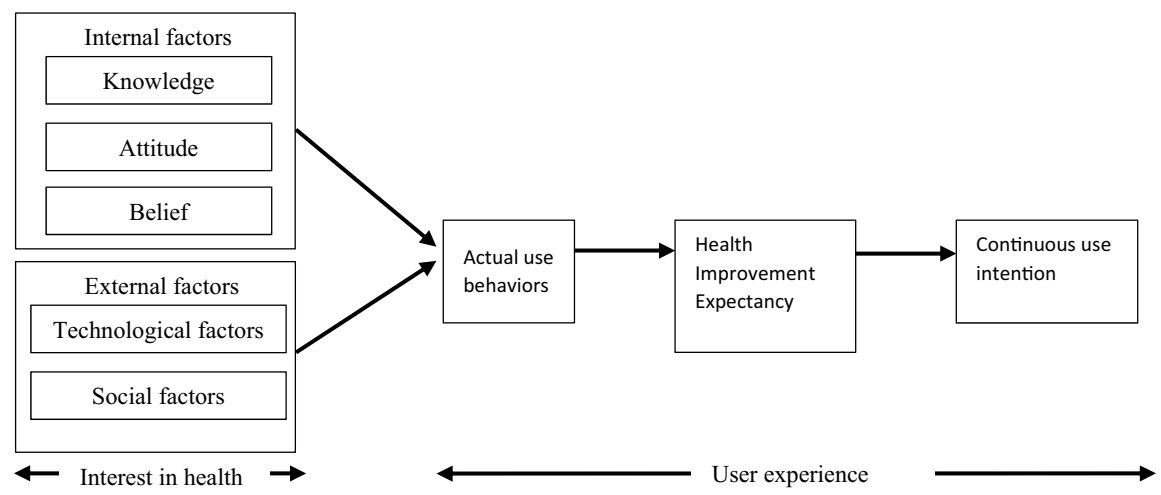

Fig. 1 Proposed research model 
health-related information rather than the health management activity itself (DuttaBergman 2004). For example, such knowledge allows one to search for appropriate health apps that suit the person's objectives and ways to practice them without difficulty.

One's drive to lead a healthy life can also influence the person's attitude. For example, an individual pursuing a healthy lifestyle would not smoke as it can cause all sorts of health problems. In other words, if one is trying to achieve an objective, the actual behavior (action) to take would require changes in the person's attitude. Believing that the use of health apps or devices would contribute to one's health can positively change his/her attitude. According to TAM, the extent to which the user believes that a system is easy to use and useful has a positive effect on use attitude and behavior toward the system (Lee et al. 2010).

Braithwaite (2018) argued that knowledge and attitudes gained by individuals in healthcare settings increased their willingness to try new activities. Likewise, Chen and Lin (2018) articulated that individuals with early-adopter characteristics tend to have the positive use intention of new healthcare applications. When a person perceives that the use of new technologies is easy and helpful, his/her internal factors would lead to proactive and positive attitudes that lead to the use intention of healthrelated devices and apps.

Generally, people with a positive orientation toward a healthy lifestyle tend to search for health-related information and are more likely to learn and apply related technologies and devices (Longo et al. 2010; Noh et al. 2013; Cho 2016). Thus, the following hypotheses are proposed.

H1: Knowledge, as part of the internal factors that lead to using a healthcare wearable device/application, affects actual use behavior.

$\mathrm{H} 2$ : Attitudes, as part of the internal factors that lead to using a healthcare wearable device/application, affect actual use behaviors.

H3: Beliefs, as part of the internal factors that lead to using a healthcare wearable device/application, affect actual use behaviors.

Healthcare wearable devices that provide real-time health information and monitoring are recognized as a valuable support tool for an individual's health. Healthcare wearable devices can have a significant influence on health-conscious people because they collect, store, and transmit various pieces of information related to health and fitness. If individuals perceive that the services or functions of an application or device are valuable, then they would be positively influenced on the use intention. Therefore, when a healthcare application/device is perceived as a useful technical tool, the person's use intention would lead to actual behavior.

With the advent of advanced technologies and social change, people are more sensitive to technological changes and consequently tend to be positively inclined to use them (Chen and Lin 2018). The importance of social influence was also present as a construct in UTAUT. Venkatesh et al. (2003) proposed that social influence has a positive impact on the use intention of new technologies and devices. In other words, an individual's social characteristics are influenced by others and lead the person to seek social universality. For example, if an influencer recommends the use of healthcare wearable devices, people universally would accept and use such devices. The technological characteristics of healthcare wearable devices and their 
impact on society would influence people to become future users of the devices. The technological factors (e.g., functions, ease of use, and comfortable) of a healthcare wearable device, as well as the individual and social characteristics (e.g., influence, usefulness, and importance) of the user, can have an influence on the actual behavior of the user. Therefore, the following hypotheses are suggested.

H4: Technological factors, as part of the external factors that lead to using a healthcare wearable device or application, affect actual use behavior.

H5: Social factors, as part of the external factors that lead to using a healthcare wearable device or application, affect actual use behavior.

People with high self-efficacy can develop positive expectations regarding the use of healthcare wearables or applications. Typically, individuals expect effective health management with the support of healthcare applications. Health improvement expectancy refers to the degree to which users believe that the application of a new technology will result in positive health improvement (Venkatesh et al. 2003; Bozan et al. 2015). Therefore, health improvement expectancy can be a predictor of continuous use intention (Venkatesh et al. 2003; Bozan et al. 2015).

In general, users who perceive the effectiveness of a certain behavior tend to repeat it and achieve the intended objective through its repetition (Lee et al. 2010). Thus, users who focus on the objective of health management by using healthcare wearables and applications will strive to achieve their health improvement expectancy goals, such as disease prevention and health management. If the results exceed expectations, individuals will tend to encourage others to try them. Therefore, users expect to achieve their health improvement expectancy goal by using healthcare wearables and applications (Lee 2018).

If a colleague or friend recommended a healthcare wearable device, the individual would develop high expectations about the device. The individual would be satisfied with the device if it provided or exceeded the expected health improvement but would become dissatisfied if the results were disappointing. Therefore, behavior for actual use influences health improvement expectancy. Furthermore, disease prevention and health information have typically been used for the supplier-centric medical services of healthcare providers. However, the emergence of a diverse range of healthcare devices and applications has helped shift this trend to user-centric healthcare services, leading many consumers to use wearable devices for health improvement expectancy (Lee 2018). Hence, the following hypothesis is proposed.

H6: The actual use behavior of healthcare wearable devices/applications has a positive effect on health improvement expectancy.

The continuous use intention refers to the willingness of the user to continue using specific products and services in the future (Bhattacherjee 2001). In a study conducted to identify factors that affect the use intention of home-based remote health services for the elderly, Cimperman et al. (2016) found that the health improvement expectancy directly influences service use intentions of home-based remote health services. A high level of belief in the use of healthcare wearable devices triggers the expected value of the devices for health management, which will lead to use intention. In addition, when users believe that the application of healthcare wearable devices is convenient for monitoring and preventing health issues, they will be willing to continue using them. In other words, believing that usage of a healthcare 
wearable device would lead to improving one's expected health could lead to the intention to use the said technology or device.

The continuous use intention can be an important contributor to health improvement expectancy as it is a result of customer satisfaction. As customer satisfaction is enhanced when customers' expectations are met, health improvement expectancy will influence continuous use intention. The following hypothesis is developed.

H7: Health improvement expectancy associated with the use of healthcare wearable devices/applications has a positive effect on continuous use intention.

\section{Research methodology}

\subsection{Data collection}

To test the proposed research model with associated hypotheses, we collected data from medical personnel and general public through a survey questionnaire. As most of the measurement items in the questionnaire were from previous studies, we undertook the double translation protocol (Harkness 2011). The questionnaire was first developed in English and then was translated into Korean by a bilingual faculty member in the service operations management area. The Korean version of the questionnaire was then translated back into English by another bilingual faculty in the healthcare management field. Three bilingual faculty examined the two English versions and found no significant difference.

The questionnaire was tested in a pilot survey involving thirty-five participating volunteers (15 medical personnel and 20 general public). After the pilot study, several measurement items of the constructs were modified because the survey participants found them ambiguous and difficult to answer. We distributed 500 questionnaires of the final version to each group: medical personnel and general public. For the medical personnel group, we randomly selected doctors, nurses, medical technicians, and pharmacists at several general hospitals that accepted our request for data collection, as well as staff at public health centers. For the general public group, we also randomly selected volunteers among businesspeople, visitors to health centers or hospitals, university employees, and college students. We factored in respondents' behavior to minimize respondent variance in each group. Subsequently, a total 288 useable questionnaires were received (a response rate of 28.8 for the sample group); medical personnel-129 out of 500 questionnaires distributed (a response rate of $25.8 \%$ ); general public-159 of 500 distributed (a response rate of $31.8 \%$ ). The final questionnaire is shown in Table 1 and provides measurement items for knowledge, attitude, belief, technological and social factors, actual use behavior, health improvement expectancy, and continuous use intention.

The characteristics of respondents are summarized in Table 2. The categorized respondent types are medical personnel (44.79\%) who are engaged in the healthcare field and general public $(55.21 \%)$ representing non-healthcare related persons. In the sample, $100 \%$ of the respondents had experience using healthcare wearable devices/apps, $87.85 \%$ for more than one year. The three types of healthcare wearable devices/apps the respondents have used are smartwatch 


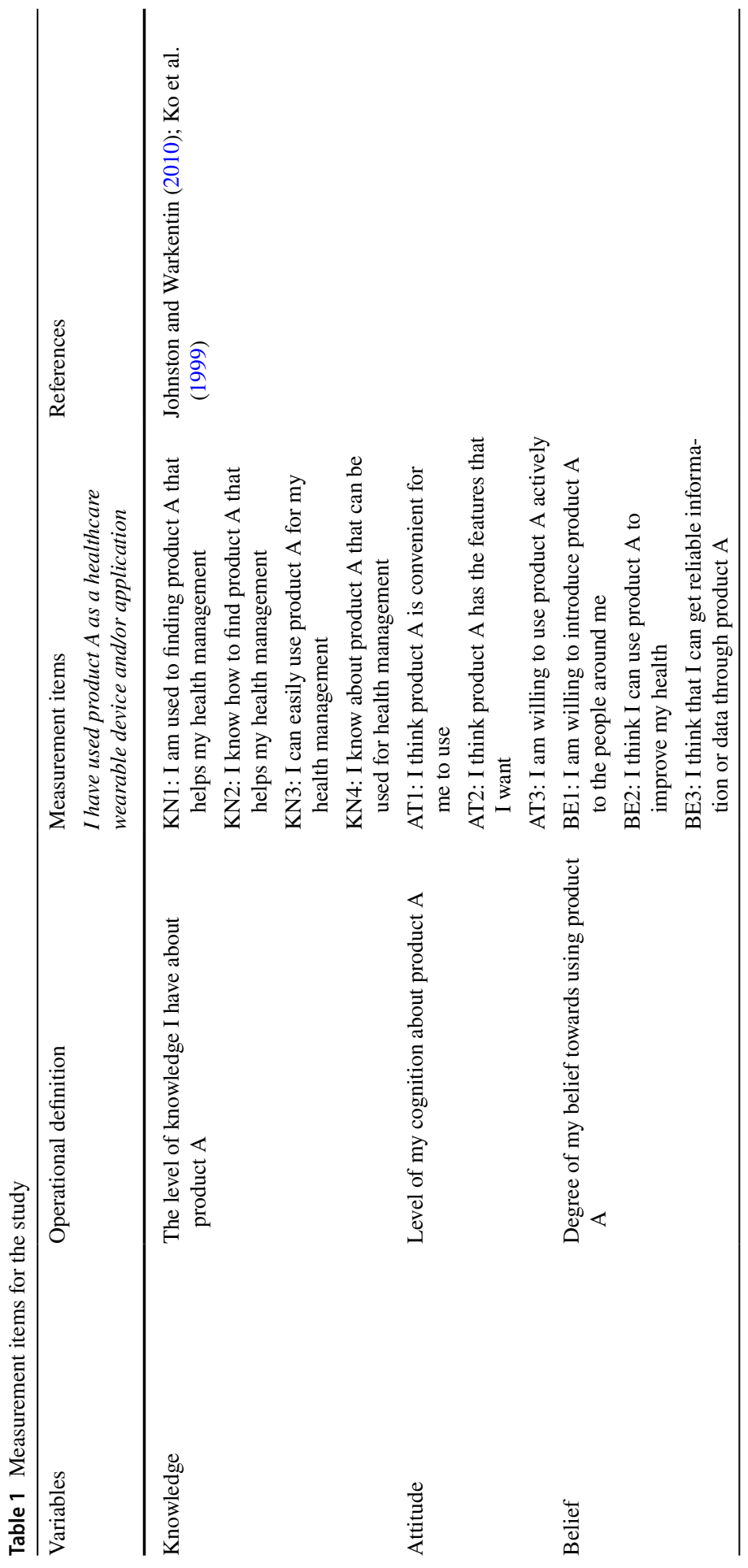




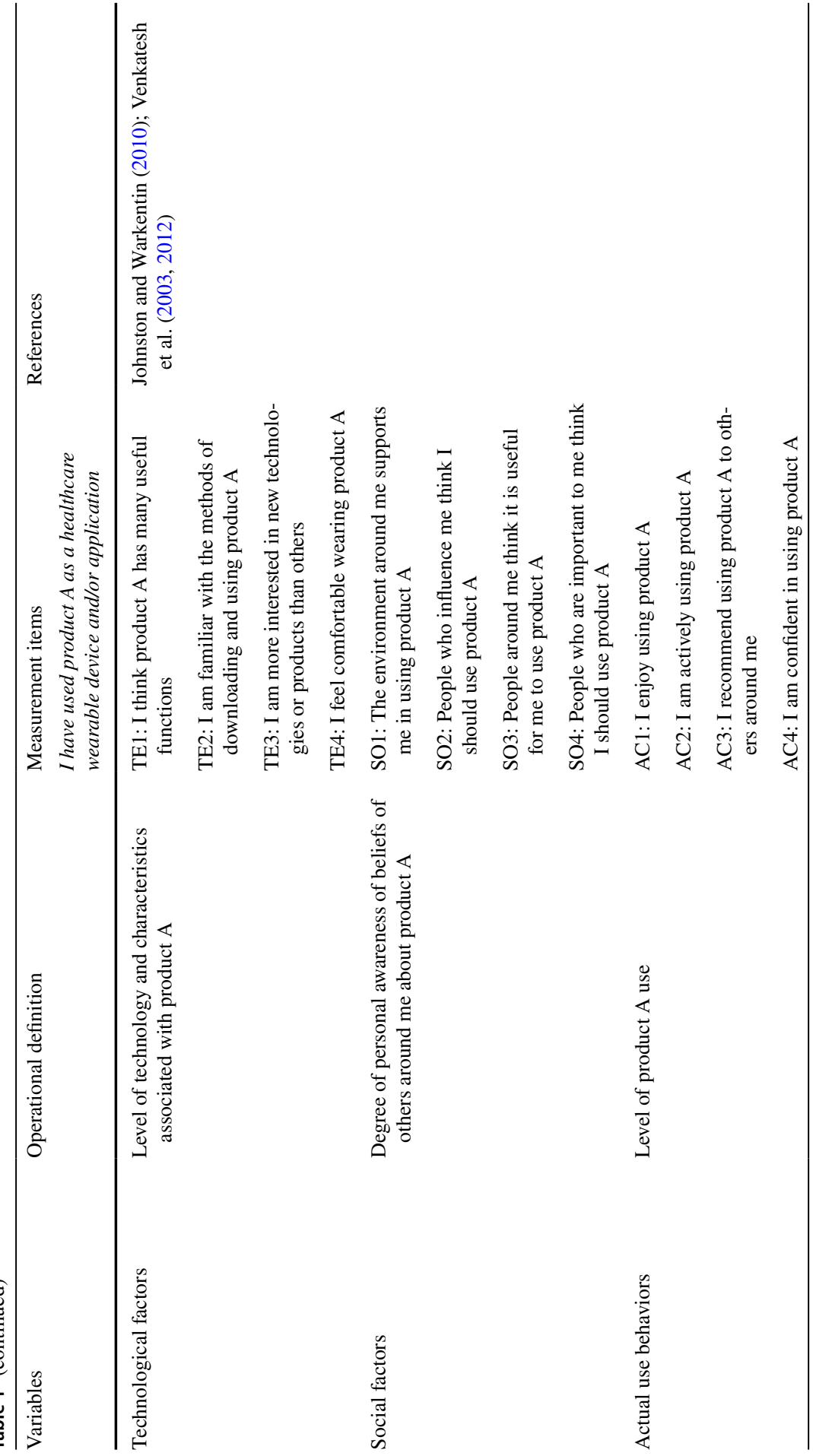




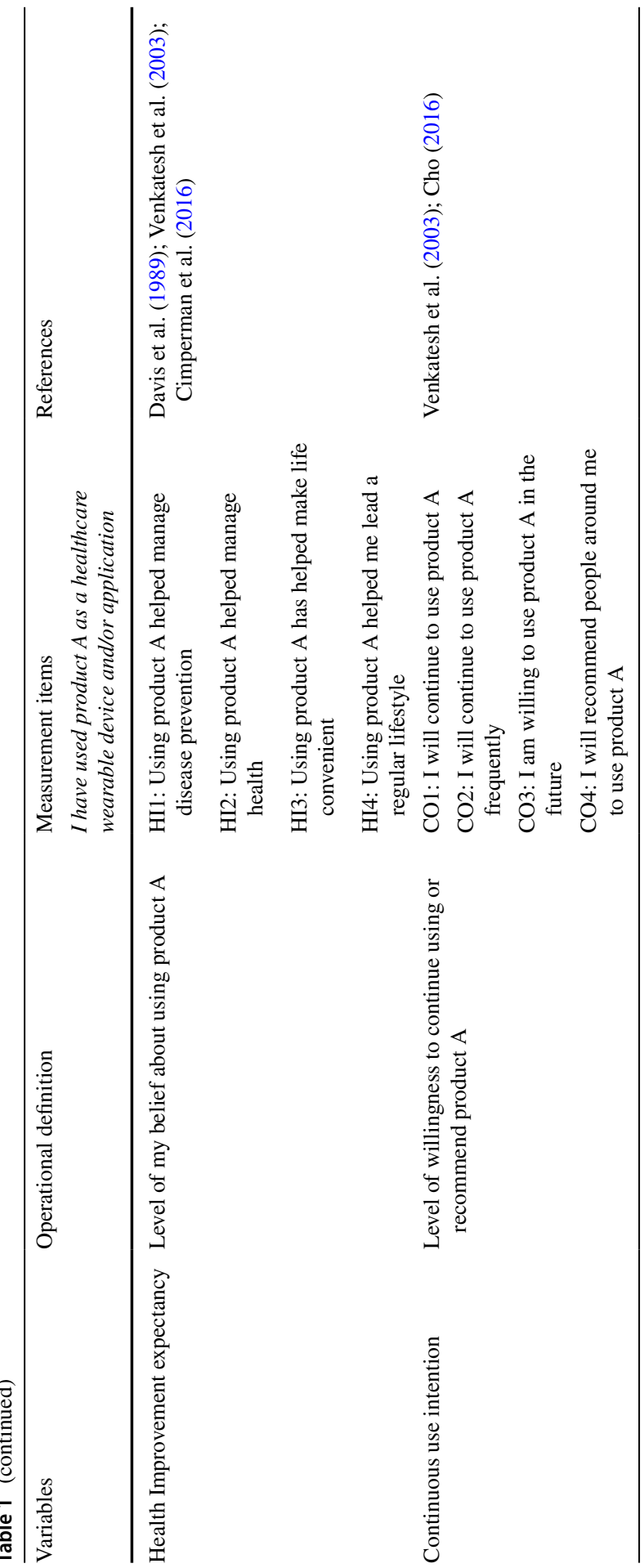




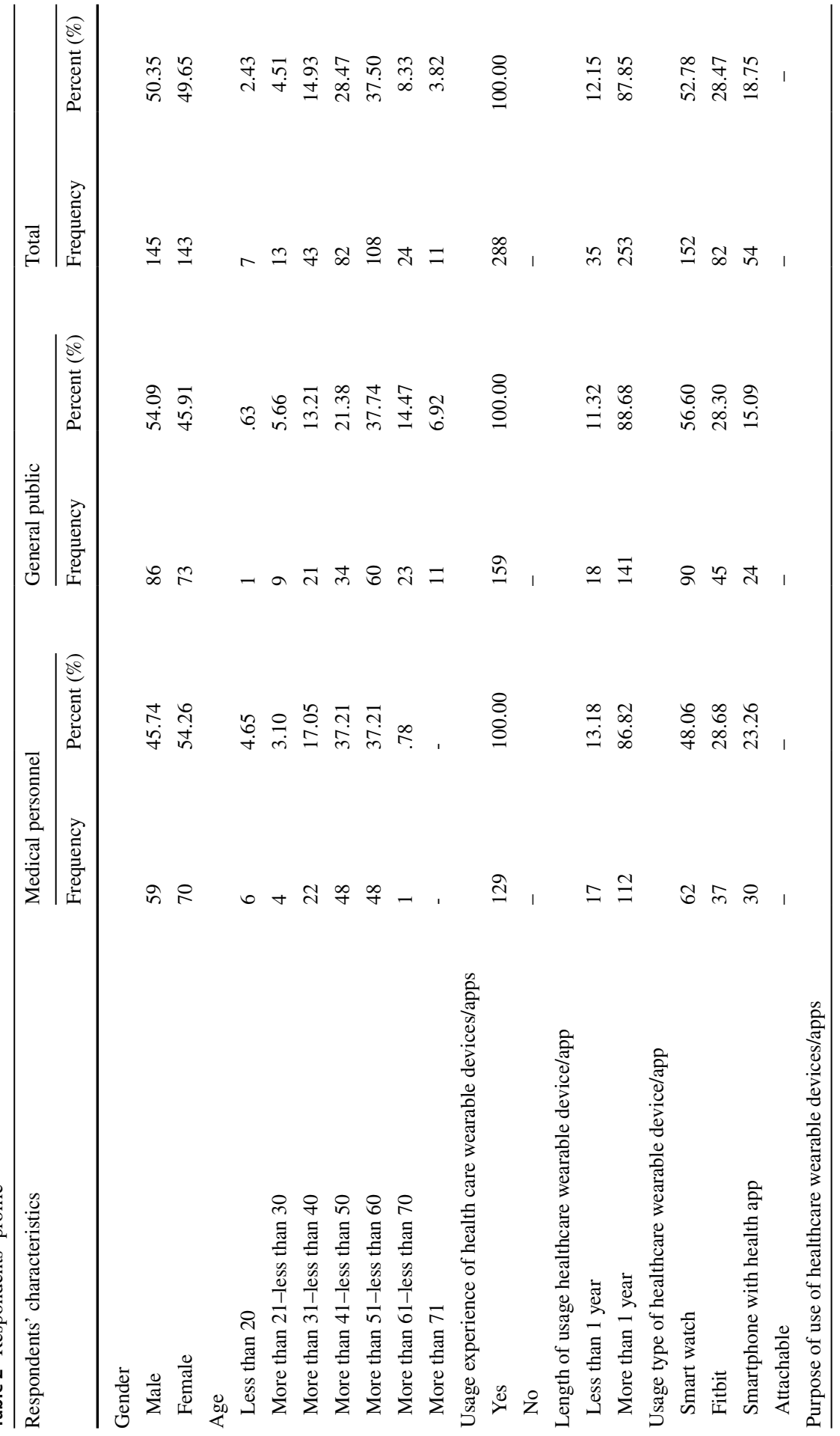




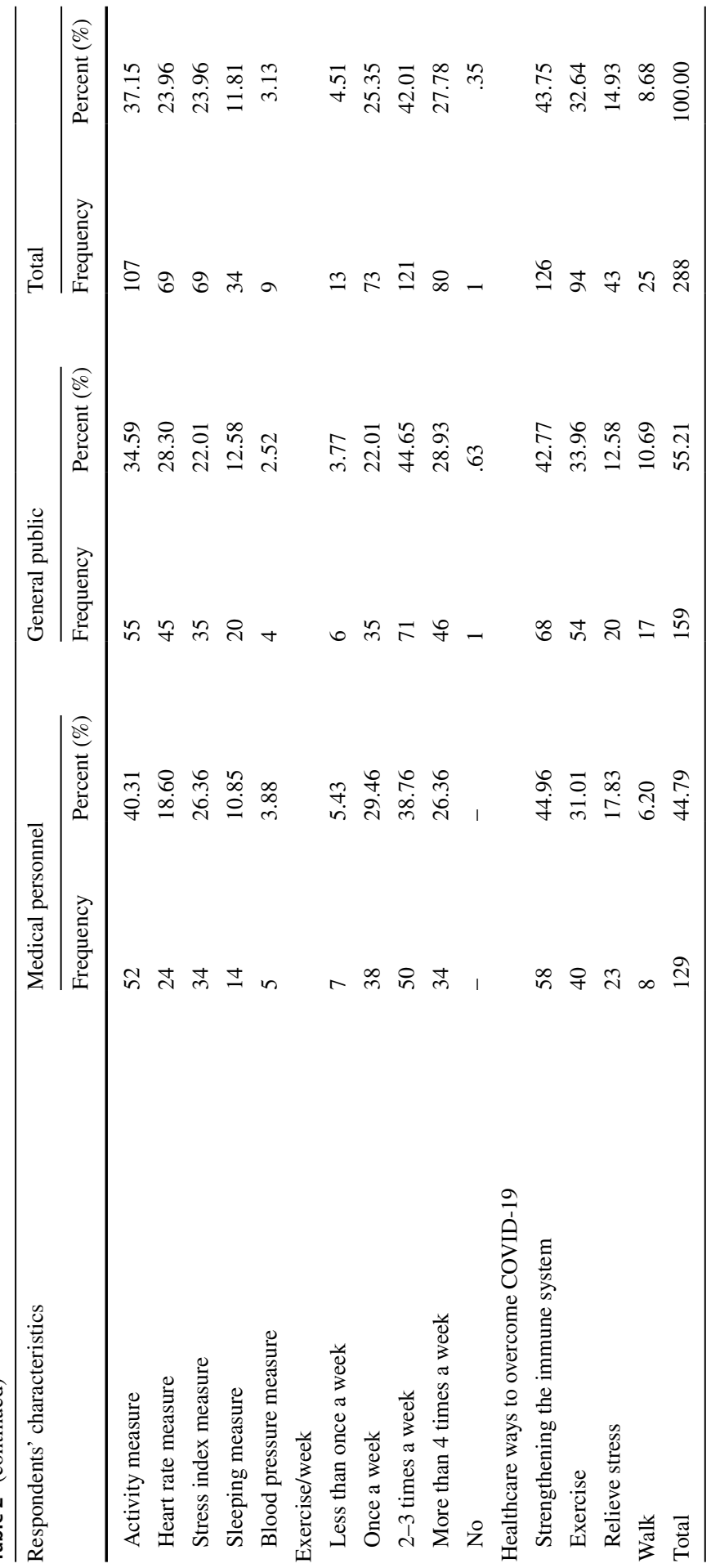


(52.78\%), Fitbit (28.47\%), and smartphone with health apps (18.75\%). The main purpose of using healthcare wearable devices/apps was listed in the following order: activity measure $(37.15 \%)$, heart rate $(23.96 \%)$, stress index $(23.96 \%)$, sleeping (11.81\%), and blood pressure (3.13\%). To overcome an uncertain crisis like COVID-19, respondents thought healthcare devices/apps can help strengthen the following: immune system $(43.75 \%)$, exercise $(32.64 \%)$, relieve stress $(14.93 \%)$, and walk $(8.68 \%)$.

\subsection{Variables of the model}

The questionnaire utilized 5-point Likert scales to measure the constructs. Measurement items from previous studies were modified to fit this research. This study employed SPSS 23.0 and AMOS 23.0 programs. Structural equation modeling (SEM) was chosen because it provides the tools necessary to test the hypotheses.

Reliability is estimated using Cronbach's alpha values (Table 3). All the coefficients for the constructs exceeded the threshold value of .70 for exploratory constructs (Nunnally 1978). In the reliability test, Cronbach's alpha for social factors was the highest (.839) and knowledge was the lowest (.727). All the Cronbach's alpha values were significant at $p<.05$.

Table 4 presents the fit indices of CFA for the whole sample, group1, and group2. Based on the recommended threshold values, CFI, RMR SRMR, RMSEA, and $\chi^{2} / \mathrm{df}$ were satisfactory for the whole sample model, but not GFI. Group1 and group2 satisfied all the recommended values.

As validity refers to the accuracy of measurement items, confirmatory factor analysis (CFA) is a way of testing how well measured variables represent the constructs for the study. Table 3 shows the standardized factor loadings and t-values for measurement variables and results of CFA to test measurement models for the whole sample, Group1 (medical personnel), and Group2 (general public), using the AMOS program. The values of standardized regression weights for knowledge, attitude, belief, technological factors, social factors, actual use behaviors, health improvement expectancy, and continuous use intention were all greater than .5 , indicating all variables proposed by the study were statistically significant at the .05 level.

The convergent validity, which requires the average variance extracted (AVE), should be greater than .5 (Fornell and Larcher 1981). All measurement items met the threshold value as shown in Table 5. Since the values of composite reliability (CR) of knowledge, attitude, belief, technological factors, social factors, actual use behaviors, health improvement expectancy, and continuous use intention were all greater than .7, convergent validity was satisfied. The off-diagonal elements are the correlation between latent variables in Table 5. For adequate discriminant validity, the square root of the AVE of any latent variable should be greater than the correlation between a given latent variable and other latent variables (Barclay et al. 1995). As shown in Table 5, statistics satisfied this requirement, lending evidence of discriminant validity. 


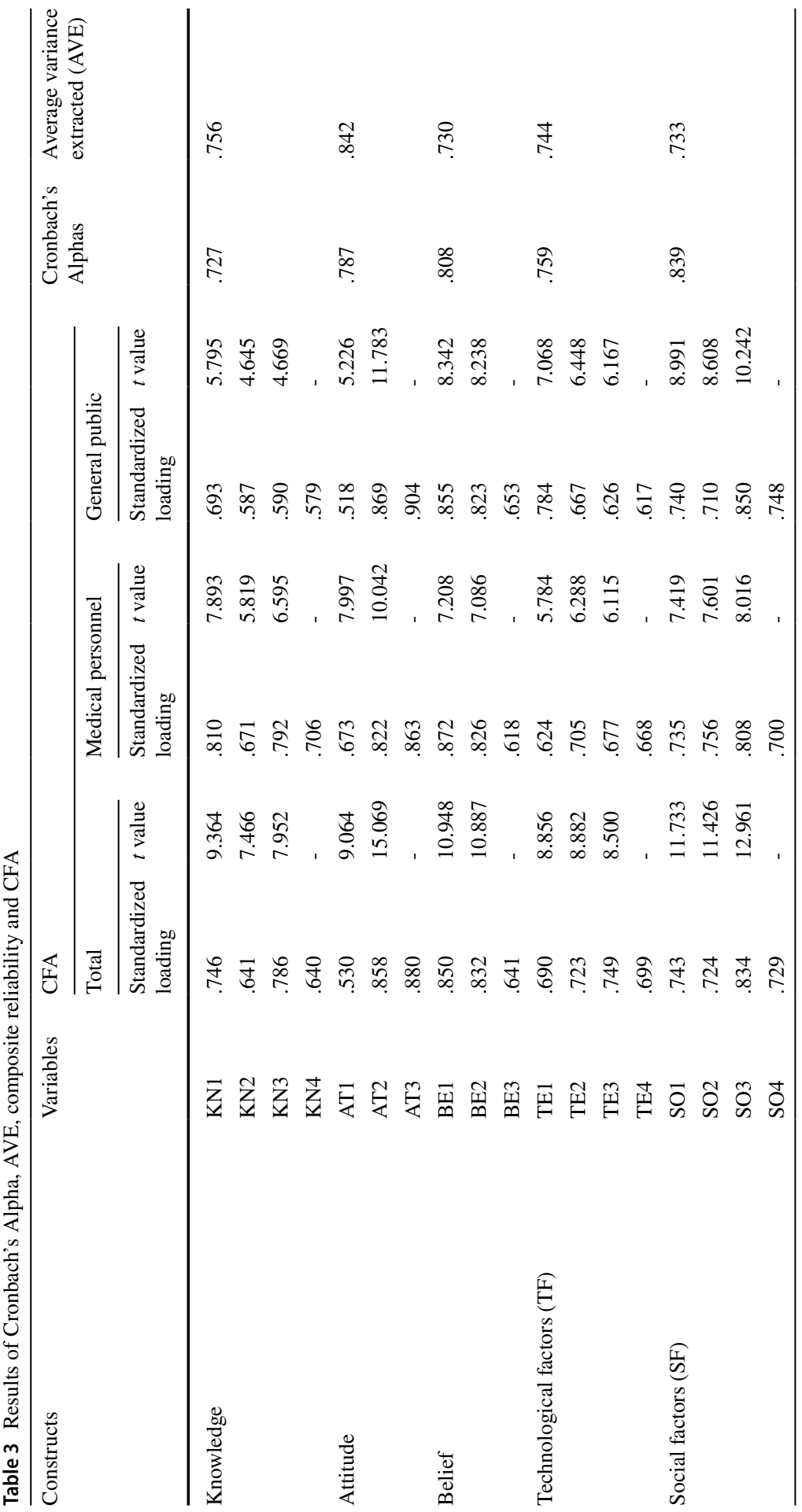




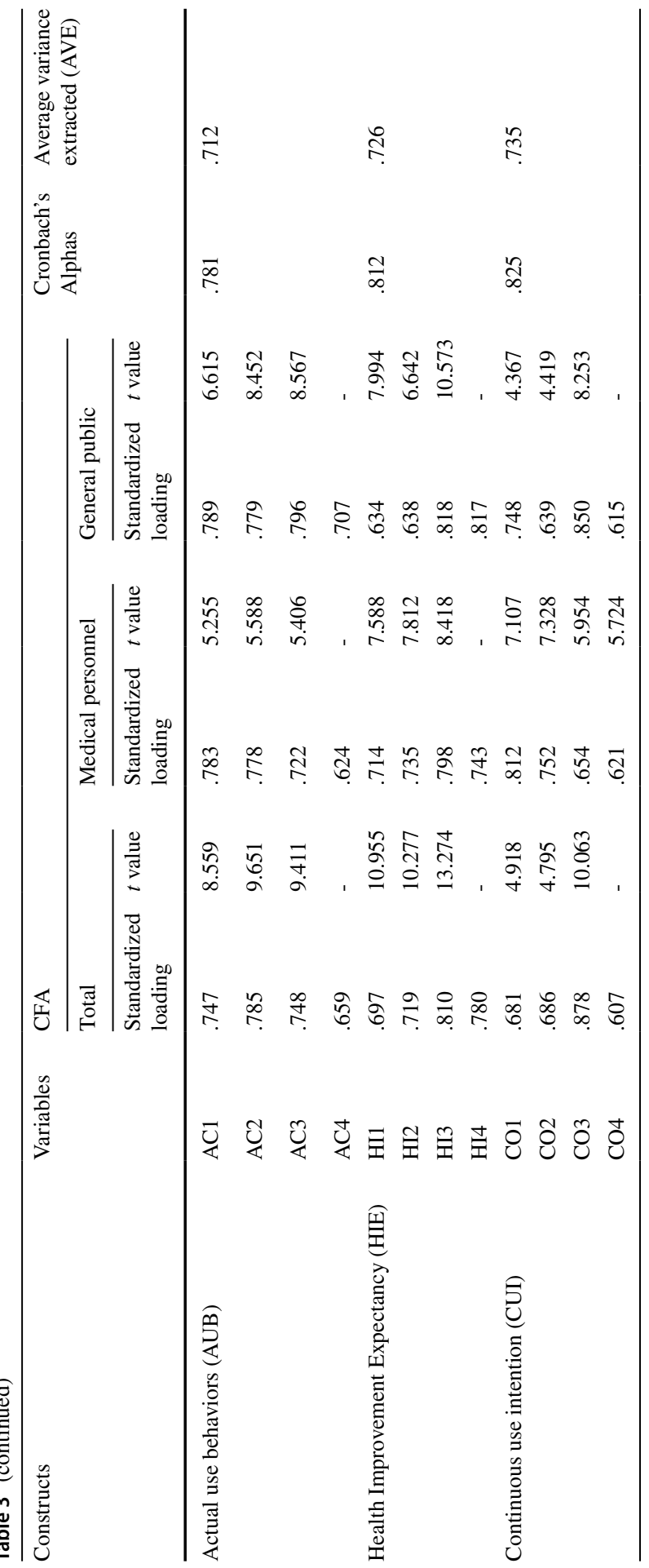


Table 4 Results of fit indices for CFA

\begin{tabular}{llcccccc}
\hline Model & $\chi^{2}$ & $\chi^{2} / \mathrm{df}$ & GFI & CFI & RMR & SRMR & RMSEA \\
\hline The entire sample & 1721.141 & 2.295 & .891 & .937 & .057 & .064 & .047 \\
Group1 (medical personnel) & 1507.657 & 2.010 & .854 & .875 & .079 & .073 & .063 \\
Group2 (general public) & 1346.662 & 1.796 & .873 & .893 & .066 & .079 & .050 \\
Recommended values & & $\leq 3.0$ & $\geq .9$ & $\geq .9$ & $\leq .08$ & $\leq .08$ & $\leq .08$ \\
\hline
\end{tabular}

GFI goodness of fit index, CFI comparative fit index, $R M R$ root mean square residual, SRMR standardized root mean square residual, RMSEA root mean square error of approximation

Table 5 Results of correlation matrix, CR and AVE

\begin{tabular}{lllllllll}
\hline Factor & Knowledge & Attitude & Belief & TF & SF & AUB & HIE & CUI \\
\hline Knowledge & 1 & & & & & & & \\
Attitude & $.284^{*}$ & 1 & & & & & & \\
Belief & $.323^{*}$ & $.433^{* *}$ & 1 & & & & & \\
TF & $.358^{*}$ & $.510^{* *}$ & $.500^{* *}$ & 1 & & & & \\
SF & $.416^{* *}$ & $.592^{* *}$ & $.502^{* *}$ & $.420^{* *}$ & 1 & & & \\
AUB & $.484^{* *}$ & $.477^{* *}$ & $.489^{* *}$ & $.516^{* *}$ & $.596^{* *}$ & 1 & & \\
HIE & $.769^{* *}$ & $.350^{*}$ & $.333^{*}$ & $.415^{* *}$ & $.417^{* *}$ & $.442^{* *}$ & 1 & \\
CUI & $.218^{*}$ & .198 & $.328^{*}$ & .170 & $.213^{*}$ & .179 & $.322^{*}$ & 1 \\
CR & .925 & .954 & .889 & .921 & .916 & .908 & .914 & .916 \\
AVE & .756 & .842 & .730 & .744 & .733 & .712 & .726 & .735 \\
Sqrt (AVE) & $\mathbf{. 8 6 9}$ & .917 & $\mathbf{. 8 5 4}$ & $\mathbf{. 8 6 3}$ & $\mathbf{. 8 5 6}$ & $\mathbf{. 8 4 3}$ & $\mathbf{. 8 5 2}$ & $\mathbf{. 8 5 7}$ \\
\hline
\end{tabular}

$\mathrm{CR}($ Composite Reliability $)=\sum$ (factor loading $)^{2} /\left[\sum \text { (factor loading }\right)^{2}+\sum$ (error) $]$

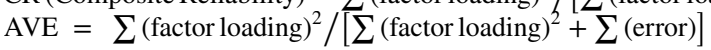

$* p<.05$

$* * p<.01$

\section{Structural equation modeling and hypothesis testing}

After examining the measurement model using partial least squares, the relations between the constructs were addressed. The hypotheses were tested by exploring the path coefficients. As a result of the goodness of fit test, compared to the recommended values, in this model, the values of CFI (.918), RMSEA (.053), RMR (.067), SRMR (.072), and $\chi^{2} / \mathrm{df}$ (2.289) were good fit indices, but GFI (.830) was below the required threshold.

Table 6 presents the result of the significance test for the research model with hypotheses. For H1, H2, and H3, the standardized path coefficient between actual use behaviors and knowledge (H1), attitudes (H2), and beliefs (H3) were .436, .177, and .174 , respectively. These three hypotheses were statistically significant at the .01 level and thus supported. The results of this study are similar to that of previous studies of the users with high internal knowledge, attitudes, and beliefs about the use of healthcare wearable devices/apps that more likely would lead to their actual 
Table 6 Results of significance test for paths of the model

\begin{tabular}{llllll}
\hline Path & Path coefficient & S.E. & $t$ value & $p$ value & Hypothesis test \\
\hline Knowledge $\rightarrow$ actual use behaviors & .436 & .067 & 5.859 & $.000 * * *$ & Supported H1 \\
Attitudes $\rightarrow$ actual use behaviors & .177 & .037 & 2.930 & $.001 * *$ & Supported H2 \\
Beliefs $\rightarrow$ actual use behaviors & .174 & .067 & 2.928 & $.003 *$ & Supported H3 \\
Technological factors $\rightarrow$ actual use behaviors & .155 & .047 & 2.442 & $.015^{*}$ & Supported H4 \\
Social factors $\rightarrow$ actual use behaviors & .153 & .043 & 2.401 & $.018^{*}$ & Supported H5 \\
Actual use behaviors $\rightarrow$ health improvement & .976 & .160 & 6.613 & $.000^{* *}$ & Supported H6 \\
$\quad$ expectancy & & & & & \\
Health improvement & .337 & .084 & 3.860 & $.000 * *$ & Supported H7 \\
$\quad$ expectancy $\rightarrow$ continuous use intention & & & & & \\
\hline$* p<.05$ & & & & &
\end{tabular}

use (e.g., Cho 2016; Chen and Lin 2018). This means that the actual use of the healthcare wearable devices/apps is based on the users' knowledge about healthcare, changing attitudes toward healthcare, and belief in using devices.

For $\mathrm{H} 4$ and $\mathrm{H} 5$, the standardized path coefficients between actual use behavior and technological factors (H4) and social factors (H5) were .155 and .153, respectively, and statistically significant at the .05 level, supporting both hypotheses. These results are also similar to those of previous studies (e.g., Venkatesh et al. 2003; 2012; Chen and Lin 2018). For example, if users can easily access certain technology systems, then lead to actual use behavior. The new healthcare wearable devices/ apps can invoke actual use behavior to create value through easy access to technology systems.

For H6, the standardized path coefficient between actual use behavior and health improvement expectancy was .976 , and statistically significant at the .001 level, supporting the hypothesis. For H7, the standardized path coefficient between health improvement expectancy and continuous use intention was .337 , and statistically significant at the .001 level, also supporting H7. These results are similar to that shown by previous studies, the higher the expected performance for health improvement through the device the higher the intention to use continuously (e.g., Venkatesh et al. 2003; 2012; Bonzan et al. 2015; Cimperman et al. 2016). If inpatients had a positive health improvement experience with healthcare wearable devices/apps, they tend to share their experiences and recommend others to use devices/apps. It means that direct or indirect experiences or expected values impact on continuous use intention of wearable devices/apps.

\subsection{Comparative analysis of the two groups}

This study collected data from two groups: medical personnel and general public. Medical personnel refer to a group of people who are always exposed to disease treatment/prevention and health promotion situations, while general public refers 
to a group that is not. Structural equation modeling (SEM) with AMOS 23 was employed to conduct a comparative analysis of the two groups to discover whether different conditions may moderate the relationships among the constructs under study.

To examine the model comparing the two groups, the study employed covariance matrices to perform a measurement equivalence test via confirmatory factor analysis (CFA) in AMOS Version 23. This allowed us to examine various combinations of constrained and unconstrained models to determine "the source of any differences in the way the constructs are composed and interpreted in the different cultures" (Myers et al. 2000).

The results of the CFA model comparing the two groups are shown in Table 7. First, Model 1 produced a $\chi^{2}$ of $1450.690(\mathrm{df}=764)$, a CFI of .930 , and an RMSEA of .056. The second model (Model 2) was executed to determine whether the measurement model is equivalent to the two groups. The $\chi^{2}$ difference between models 1 and 2 was non-significant $\left(\Delta \chi^{2}=1.289\right)$. This suggests that the measurement scale is assumed to be equivalent across the two groups (Myers et al. 2000). Model 3, constrained for factor correlations $(\Phi)$ and factor loadings $(\lambda)$, was not significantly different from model $2\left(\Delta \chi^{2}=1.092\right.$, df $=2$; CFI $=.929$; RMSEA $\left.=.055\right)$. This finding implies that factor correlations and factor loadings are constrained such that they are equal (Myers et al. 2000). Model 4 estimated the error variances $(\theta)$ to be equal across the two groups. Model 4 was significantly different from Model $1\left(\Delta \chi^{2}\right.$ $=13.34 ; \mathrm{df}=17$; CFI $=.906 ;$ RMSEA $=.055$ ). Based on Table 7, we are assured that the measurement items for each construct have high convergent and construct validity to test the research model for each group.

The results of the comparative analysis for the two groups with path coefficients (medical personnel and general public) are shown in Table 8. All path loadings were significant at the .05 level. The effect of health improvement expectancy on continuous use intention was supported for both groups (H7: $\beta=.336$ and $\beta=.346$, respectively). The following hypotheses were supported for both groups: the effect of knowledge on actual use behavior $(\mathrm{H} 1: \beta=.425$ and $\beta=.456$, respectively); the effect of attitudes on actual use behavior ( $\mathrm{H} 2: \beta=.249$ and $\beta=.337$, respectively); the effect of beliefs on actual use behavior $(\mathrm{H} 3: \beta=.315$ and $\beta=.163$, respectively); the effect of technological factors on actual use behavior (H4: $\beta=.314$ and $\beta=.172$, respectively); the effect of social factors on actual use behavior (H5: $\beta=.247$ and $\beta$ $=.252$, respectively): and the effect of actual use behavior on health improvement expectancy (H6: $\beta=.696$ and $\beta=.476$, respectively). As shown in Table 8, overall,

Table 7 Results of CFA model comparison

\begin{tabular}{llllllll}
\hline Model & $\chi^{2}$ & df & $p$ value & CFI & RMSEA & $\Delta \chi^{2} / \mathrm{df}$ & $\Delta^{2}$ Sig. Diff. \\
\hline Unconstrained (model 1) & 1450.690 & 764 & .000 & .930 & .056 & & \\
$\lambda$ Constrained (model 2) & 1451.979 & 767 & .000 & .930 & .055 & $1.289 / 4$ & No \\
$\Phi, \lambda$ Constrained (model 3) & 1453.071 & 779 & .000 & .929 & .055 & $1.092 / 2$ & No \\
$\Phi, \lambda, \theta$ Constrained (model 4) & 1464.030 & 781 & .000 & .906 & .055 & $13.34 / 17$ & Yes \\
\hline
\end{tabular}




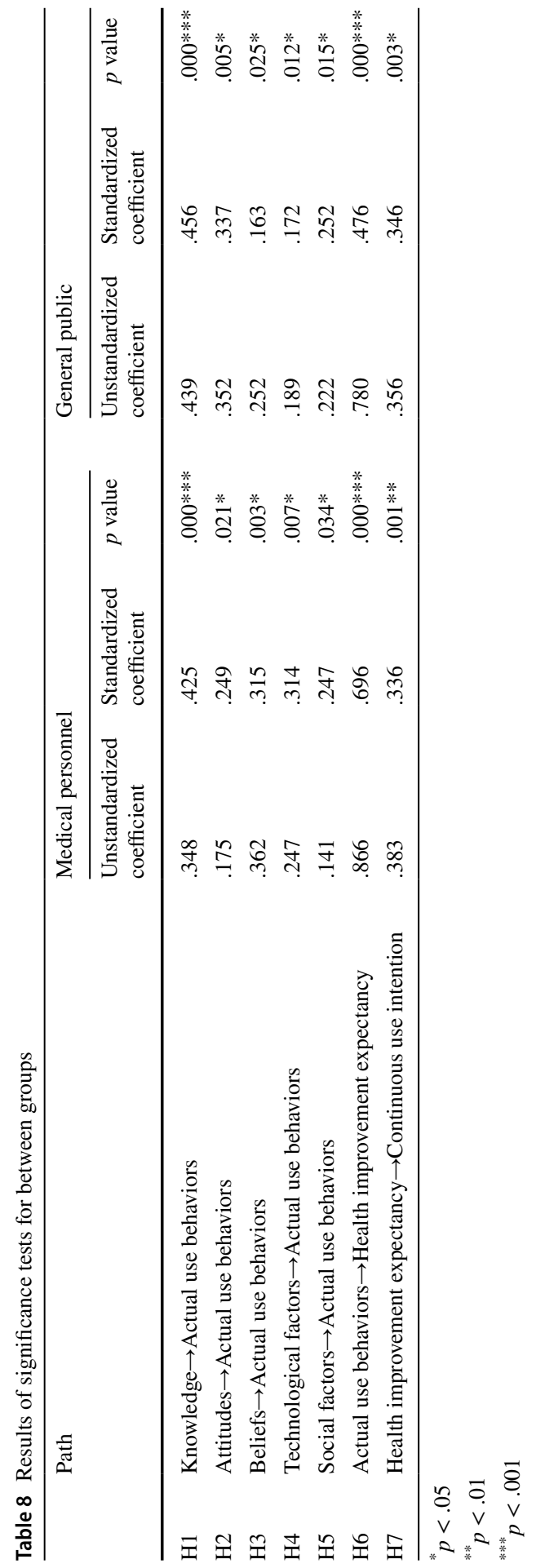


the medical personnel group showed a higher degree of relationships between factors on unstandardized coefficient. The coefficients and significant values were different between the two groups as well.

\section{Conclusion}

This study combined KABP, TPB, and UTAUT2 models for an empirical analysis of factors that influencing the continuous use intention of healthcare wearable devices or applications. Furthermore, the study performed a comparative analysis of the two groups in the sample: medical personnel and general public. A research model, along with associated hypotheses, was proposed. The results of the study revealed that continuous use intention of healthcare wearable devices/apps should be prioritized for improving health conditions or preventing diseases.

The study results confirmed the positive effects of knowledge (H1), attitudes (H2), and beliefs (H3) of internal factors on actual use behavior of healthcare wearables/apps. These results shed new insights about how healthcare wearable device manufacturers can develop their products to increase user intention to use them. The actual use behavior is influenced by internal factors. The study also found positive relationships between actual use behavior and technological factors (H4) and social factors (H5), as part of external factors. Since the actual use behavior is influenced by social trends and convenience of using technology, it is important to provide a good user experience. These results indicate that both internal and external factors are important for increasing actual use behavior, based on the social and technical demands of customers. In addition, the results of the study revealed positive relationships between actual use behavior and health improvement expectancy $(\mathrm{H} 7)$.

Humphis (2000) suggested that "improved population health depends on changing the behavior of people," such as who are healthy (e.g., people with regular exercise regime), who are ill (e.g., heavy smokers), and how health promotion is delivered (e.g., community health clubs). The study results confirmed that all proposed hypotheses were supported for both groups (medical personnel and general public: H1, H2, H3, H4, H5, H6, and H7). However, overall, the medical personnel group showed higher levels of significance in the relationships than the general public group. Since medical staffs are always concerned with healthcare, they are highly willing to use wearables/apps with high expectations for improved health management. With the current COVID-19 pandemic crisis around the globe, the interest in healthcare wearables/apps has increased tremendously (Phaneuf 2020). Especially, there is a strong new trend for "untact" healthcare services, such as e-healthcare or tele-healthcare (Lee and Lee 2020). Considering these uncertainties, it is reasonable to assume that the demand for healthcare wearables/apps will continue to increase in the future (Lee and Lee 2020; Phaneuf 2020).

The values of explanatory power $\left(\mathrm{R}^{2}\right)$ of the five antecedent variables on actual use behaviors are as follows: knowledge: $.127(F=41.554)$, attitudes: $.176(F=61.268)$, beliefs: $.163(F=55.523)$, technological factors: $.164(F=56.310)$, and social factors: $.277(F=109.626)$. Although the explanatory power values $\left(0<\mathrm{R}^{2}<1\right)$ appear to be low, they were significant at $p<.000$. The results indicated that social factors variable 
was most significant among five antecedent variables for actual use behaviors and continuous use intention of healthcare wearables/apps. The greatest significance shown by social factors imply that most people are influenced by their social surroundings for using or continuous use intention of healthcare wearables.

The results of the study have significant practical implications for the healthcare industry. The healthcare environment has witnessed a shift from treatment-centered services to prevention and management-centered services with the patient's self-control and use of advanced healthcare devices (Lee 2018; Lee and Lee 2020). In addition, public interest in health has grown significantly with the aging population, which has given rise to demands for customized healthcare services with self-management or heath control devices. Today, there is a diverse type of smart healthcare wearable devices, tools, or apps available and new ones are being introduced to the market (e.g., AliveCor's personal EKG, TEMPTRAQ to monitoring the temperature, Blinq wearable rings, Philips smart sleep, Wireless patient monitoring, etc.). Health-related institutions and policymakers should make it easy and simple to use wearable devices. Manufacturers of wearable devices should lower the price of their products so that general public can purchase and use them for their health benefits. Lindhult et al. (2018) suggested that product-oriented manufacturing companies need to understand consumer needs and pursue service innovation to create greater value for consumers. Therefore, the results of this study can provide practical guidelines for the producers of healthcare wearables/apps that may provide value for the greater good.

The results of this study can also be useful for developing new remote healthcare services through mobile devices. While this study yielded interesting results, it also has several limitations. The study is based on the data collected from the users of user-centric healthcare wearable devices and applications; however, it did not analyze the specific characteristics of these devices and applications. Therefore, it is necessary to apply the results of this study after identifying the functions and services expected by the users. This study did not comprehensively examine the influence of individual user's characteristics, health status, and the sustainable use intention of wearables or apps. These limitations provide future research opportunities. It is also important to consider how new or additional health data can be generated and used by wearables and apps. This is a sensitive area that involves data security, privacy, and the digitalization of healthcare data. There are many new future research opportunities in this area, such as contact tracing for the COVID-19 infected patients using such wearable devices.

Funding This work was supported by INHA UNIVERSITY Research Grant.

\section{References}

Abraham C, Sheeran P (2015) The health belief model. In: Conner M, Norman P (ed) Predicting and changing health behavior: research and practice with social cognition models, $3^{\text {rd }}$, McGraw Hill Education, NY, 30-69

Aitken M, Lyle J (2015) Patient adoption of mHealth: use, evidence and remaining barriers to mainstream acceptance. IMS Institute for Healthcare Informatics, Parsippany, NJ 
Ajzen I (2002) Perceived behavioral control, self-efficacy, locus of control, and the theory of planned behavior. J Appl Soc Psychol 32(4):665-683

Ajzen I (1998) Models of human social behavior and their application to health psychology. J Psychol Health 13(4):735-739

Al-Tarawneh J (2019) Technology acceptance models and adoption of innovations: a literature review. Int J Sci Res 9(8):833-857

Armitage C, Christian J (2003) From attitudes to behavior: basic and applied research on the theory of planned behavior. Curr Psychol 22(3):187-195

Badran I (1995) Knowledge, attitude and practice the three pillars of excellence and wisdom: a place in the medical profession. East Mediterr Health J 1(1):8-16

Bandura A (1997) Self-efficacy: the exercise of control. Worth Publishers Inc., NY

Barclay D, Thompson R, Higgins C (1995) The Partial Least Squares (PLS) approach to causal modeling: personal computer adoption and use as an illustration. Technol Stud 2(2):285-309

Becker M, Haefner D, Maiman L (1977) The health belief model in the prediction of dietary compliance: a field experiment. J Health Soc Behav 18:348-366

Bhattacherjee A (2001) Understanding information systems continuance: an expectation-confirmation model. MIS Q 25(3):351-370

Bozan K, Davey B, Parker K (2015) Social influence on health IT adoption patterns of the elderly: an institutional theory-based use behavior approach. Procedia Comp Sci 63:517-523

Braithwaite J (2018) Changing how we think about healthcare improvement. https://www.bmj.com/conte $\mathrm{nt} / 361 / \mathrm{bmj} . \mathrm{k} 2014$

Chadha S, Ennen M, Parekh R, Pellumbi G (2020) Reimagining medtech for a COVID-19 world. McKinsey \& Company

Chen M, Lin N (2018) Incorporation of health consciousness into the technology readiness and acceptance model to predict App download and usage intentions. Internet Res 28(2):351-373

Cho J (2016) The impact of post-adoption beliefs on the continued use of health apps. Int J Med Inform $87: 75-83$

Cimperman M, Brenčič M, Trkman P (2016) Analyzing older users' home telehealth services acceptance behavior-applying an extended UTAUT model. Int J Med Inform 90:22-231

Cohen O, Fox B, Mills N, Wright P (2020) COVID-19 and commercial pharma: navigating an uneven recovery. McKinsey \& Company. April

Davis F (1989) Perceived usefulness, perceived ease of use, and user acceptance of information technology. MIS Q 13(3):319-340

Davis F, Bagozzi R, Warshaw P (1992) Extrinsic and intrinsic motivation to use computers in the workplace. J Appl Soc Psychol 22(14):1111-1132

Dutta-Bergman M (2004) Primary sources of health information: comparisons in the domain of health attitudes, health cognitions, and health behaviors. Health Comm 16(3):273-288

Dunsmuir D, Payne B, Cloete G, Petersen C, Görges M, Lim J, von Dadelszen P, Dumont G, Ansermino J (2014) Development of mHealth applications for pre-eclampsia triage. IEEE J Biomed Health Inform 18(6): $1857-1864$

Ericsson (2017) Ericsson mobility report. https:/www.ericsson.com/assets/local/mobility-report/docum ents/2017/ericsson-mobility-report-june-2017-rina.pdf

Fishbein M, Ajzen I (2010) Predicting and changing behavior: the reasoned action approach. Psychology Press, NY

Fornell C, Larcker D (1981) Evaluating structural equation models with unobservable variables and measurement error. J Market Res 18(1):39-50

Fox G, Connolly R (2018) Mobile health technology adoption across generations: narrowing the digital divide. Inform Sys J 26(6):995-1029

Frank E (2004) Physician health and patient care. J Am Med Assoc 291(5):637

Gücin N, Berk Ö (2015) Technology acceptance in health care: an integrative review of predictive factors and intervention programs. Procedia-Soc Behav Sci 195:1698-1704

Harkness J (2011) Guidelines for best practice in cross-cultural surveys. University of Michigan Institute for Social Research, Ann Arbor, Survey Research Center

Harris N, Garcia-Godoy F (2004) Primary preventive dentistry. $6^{\text {th }}$. Pearson Prentice Hall, Saddle River, NY, 456-460

Humphis G, Ling M (2000) Behavioral sciences for dentistry. Churchill Livingstone, London, UK, pp $118-132$ 
Johnston A, Warkentin M (2010) Fear appeals and information security behaviors: an empirical study. MIS Q 34(3):549-566

Ko SY, Moon HS, Kim JB, Paik DI (1999) A study on the knowledge, opinions and practices about oral health of workers in Korea. J Korean Acad Dent Health 23(2):95-111

Lee D (2018) Strategies for technology-driven service encounters for patient experience satisfaction in hospitals. Technol Forecast Soc Change 137(12):118-127

Lee D (2019) A model for designing healthcare service based on the patient experience. Int J Healthcare Manag 12(3):180-188

Lee D, Lee S, Olson D, Chung S (2010) The effect of organizational support on ERP implementation. Indust Manag Data Sys 110(2):269-283

Lee S, Lee D (2020) "Untact": a new customer service strategy in the digital age. Serv Bus 14(1):1-22

Lindhult E, Chirumalla K, Oghazi P, Parida V (2018) Value logics for service innovation: practice-driven implications for service-dominant logic. Serv Bus 12(1):457-481

Longo D, Schubert S, Wright B, LeMaster J, Williams Clore J (2010) Health information seeking, receipt, and use in diabetes self-management. Ann Fam Med 8(4):334-340

Markets and Markets (2017) mHealth solutions market worth 90.49 billion USD by 2022. https://www. mrketsandmarkets.com/PressReleases/mhealth-apps-and-solutions.asp

Myers M, Calantone R Jr, Page T, Taylor C (2000) An application of multiple-group causal models in assessing cross-cultural measurement equivalence. J Int Market 8(4):108-121

Noh G, Choi J, Kwon M (2013) A test of extended technology acceptance model on health information seeking on the internet. Korean J Broadcast Telecomm Stud 27(5):49-85

Nunnally J (1978) Psychometric Theory, 2nd edn. McGraw Hill, New York

O’Donovan T, O'Donoghue J, Sreenan C, Sammon D, O'Reilly P, O'Connor K (2009) A context aware wireless body area network (BAN). Pervasive Computing Technologies for Healthcare, 2009. 3rd International Conference on. IEEE

Panner M (2019) Healthcare and baby boomers: tech adoption is the key to better outcomes. Forbes

Pataranutaporn P, Jain A, Johnson C, Shah P, Maes P (2019) Wearable lab on body: combining sensing of biochemical and digital markers in a wearable device. Annual International Conference of the IEEE Engineering in Medicine and Biology Society (EMBC), Berlin, Germany, 3327-3332

Patel S, Park H, Bonato P, Chan L, Rodgers M (2012) A review of wearable sensors and systems with application in rehabilitation. J Neuro Eng Rehabilitat 9(21):1-17

Phaneuf A (2020) Latest trends in medical monitoring devices and wearable health technology. Business Insider. https://www.businessinsider.com/wearable-technology-healthcare-medical-devices

Raina S (2013) Assessment of knowledge, attitude, and practice in health care delivery. North Am J Med Sci 5(3):249-250

Rauschnabel P, Brem A, Ivens B (2015) Who will buy smart glasses? empirical results of two pre-market-entry studies on the role of personality in individual awareness and intended adoption of google glass wearables. Comput Human Behav 49:635-647

Ravindra S (2019) The role of connected wearable devices in healthcare. IoT for All. https://www.iotfo rall.com/connected-wearable-devices-healthcare/

Rav-Marathe K, Wan T, Marathe S (2016) A systematic review on the KAP-O framework for diabetes education and research. Med Res Archiv 4(1):1-21

Rosenstock I (1974) Historical origins of the health belief model. Health Educat Monogr 2:328-335

Shapiro G. (2018) Keynote speech at Hearing Loss Association of America Conference. Hyatt Regency Minneapolis, June 21-June 24, 2018 https://www.businesswire.com/news/home/20180309005107/ en/Gary-Shapiro-President-CEO-Consumer-Technology-Association

Strategy Analytics (2019) Global smartwatch vendor market share by region. https://www.strategyanalyti cs.com/

Taylor D, Bury M, Campling N, Carter S, Garfied S, Newbould J, Rennie T (2007) A review of the use of the health belief model (HBM), the theory of reasoned action (TRA), the theory of planned behaviour (TPB) and the trans-theoretical model (TTM) to study and predict health related behaviour change. National Institute for Clinical Excellence. 1-19

Taylor S, Todd P (1995) Understanding information technology usage: a test of competing models. Inform Sys Res 6(2):144-176

Venkatesh V, Davis F (2000) A theoretical extension of the technology acceptance model: four longitudinal field studies. Manag Sci 46(2):186-204

Venkatesh V, Morris M, Davis G, Davis F (2003) User acceptance of information technology: toward a unified view. MIS Q 27(3):425-478 
Venkatesh V, Thong J, Xu X (2012) Consumer acceptance and use of information technology: extending the unified theory of acceptance and use of technology. MIS Q 36(1):157-178

Wang Y, Wu M, Wang H (2009) Investigating the determinants and age and gender differences in the acceptance of mobile learning. Br J Educat Technol 40(1):92-118

Wilson E, Lankton N (2004) Modeling patients' acceptance of provider-delivered E-health. Journal of the American Medical Informatics Association 11(4):241-248

Working group on Monitoring and Evaluation (2014) Knowledge, attitudes, and practices (KAP) surveys during Cholera vaccination campaigns: guidance for oral Cholera vaccine stockpile campaigns.1-41 https://www.who.int/cholera/vaccines/kap_protocol.pdf?ua=1

Yang H, Yu J, Zo H, Choi M (2016) User acceptance of wearable devices: an extended perspective of perceived value. Telemat Inform 33(2):256-269

Yoon S, Lee D, Shin Y (2020) Innovative healthcare wearable device usage and service enhancement. Glob Bus Financ Rev 25(2):1-10

Publisher's Note Springer Nature remains neutral with regard to jurisdictional claims in published maps and institutional affiliations. 